\title{
Transdermal Therapy for Attention-Deficit Hyperactivity Disorder with the Methylphenidate Patch (MTS)
}

\author{
Robert L. Findling $\cdot$ Steven Dinh
}

Published online: 15 February 2014

(c) The Author(s) 2014. This article is published with open access at Springerlink.com

\begin{abstract}
Transdermal technology is currently approved in the US for the administration of more than 20 medications. This current review describes the clinical research pertaining to the use of a methylphenidate patch in the treatment of attention-deficit hyperactivity disorder (ADHD) in children and adolescents. PubMed searches were conducted using the search term 'methylphenidate transdermal system', and were limited to clinical trials. No limits were set for dates of publication. A total of 21 citations were identified. Studies evaluating the safety and efficacy of the methylphenidate transdermal system (MTS) in children and adolescents were included in this review. Additional studies were identified from bibliographies and the 'Related Citations' section of PubMed searches. The MTS delivers a range of methylphenidate doses using a drug-in-adhesive matrix patch. According to current labeling, the patch should be applied to the hip once daily for a maximum of $9 \mathrm{~h}$. Serum methylphenidate levels increase over wear time, with mean time to maximum concentration $\left(t_{\max }\right)$ reached between 8 and $10 \mathrm{~h}$ for a 9-h wear time, and the elimination half-life for methylphenidate is $3-4 \mathrm{~h}$ after patch removal. In clinical trials, ADHD symptoms were measured using the ADHD Rating Scale, Version IV, and several parent-, teacher-, and patient-rated scales. Treatment effects show statistically significant differences from baseline symptom scores starting at the first evaluation, $2 \mathrm{~h}$ after the patch is applied, with significant
\end{abstract}

\section{R. L. Findling ( $\square)$}

Division of Child and Adolescent Psychiatry, The Johns Hopkins Hospital, 1800 Orleans Street, Bloomberg Children's Center 12344-A, Baltimore, MD 21287, USA

e-mail: rfindli1@jhmi.edu

S. Dinh

Noven Pharmaceuticals Inc., Miami, FL, USA benefit lasting up to $12 \mathrm{~h}$ with a 9-h wear time. Adverse events with the MTS are similar to those seen with other formulations of methylphenidate, with the exception of skin-related reactions at the site of application, which were generally mild to moderate in severity. The incidence of contact allergic dermatitis with MTS is $<1 \%$. Statistically significant improvements in health-related quality of life and medication satisfaction were also observed with the MTS compared with placebo, and after switching from oral extended-release (ER) methylphenidate. Transdermal drug delivery is an effective and safe means of administering methylphenidate for patients with ADHD.

\section{Overview of Transdermal Technology}

Currently, there are more than 20 medications available in the US that use generic and branded transdermal systems [1]. These include patch products for smoking cessation, antihypertensives, pain relievers, anti-nausea medications, and hormone therapies. There is a growing trend of using transdermal delivery for agents that act in the central nervous system, such as cholinesterase inhibitors for dementia, monoamine oxidase inhibitors for depression, dopamine agonists for Parkinson's disease [2] and restless leg syndrome [2], as well as clonidine for hypertension [3] and methylphenidate for attention-deficit hyperactivity disorder (ADHD) [4].

\subsection{Potential Advantages of Transdermal Delivery}

In an effort to improve adherence to treatment, individualizing therapy is a growing trend in the management of chronic conditions. The development of transdermal systems has facilitated individualizing the duration of therapy 
for patients because a patch can be removed, stopping the delivery of medication, unlike orally administered medications which remain in the system once ingested. Transdermal absorption minimizes first-pass metabolism, hepatic side-effects, the attendant potential for drug-drug interactions, as well as the risk of gastrointestinal irritation may be reduced [1]. Steady absorption of drug through the skin may provide more consistent drug exposure during dosing and might avoid serum drug peaks and troughs [5]. This reduction of peaks and troughs may, in turn, decrease the incidence of adverse effects [1]. Long-acting (LA) transdermal patches often require less frequent dosing, which may also help improve adherence to treatment $[6,7]$.

Although there are few data regarding children and adolescents, patch technology does appear to improve adherence to treatment in a range of patient populations [68]. In one trial of a contraceptive patch, excellent adherence and no pregnancies among adolescent patients were reported [8]. In a survey of 1,470 patients with asthma or chronic obstructive pulmonary disease, $84 \%$ of patients reported that they used their tulobuterol patch as prescribed, whereas the rate was $31-64 \%$ for individuals using an inhaler [9]. Patients cited once-daily dosing as a key factor in their adherence. A study of 649 patients with mild-to-moderate dementia from Alzheimer's disease found that patients who were prescribed patches had higher rates of adherence than those receiving oral medications [7]. A survey of 1,059 caregivers showed that more than $70 \%$ preferred using a rivastigmine patch rather than capsules for the treatment of Alzheimer's patients in their care [10]. Caregivers preferred the dosing schedule, ease of use with the patch over oral administration, and reported greater overall satisfaction and less interference with daily life when using the patch.

\subsection{Potential Limitations of Transdermal Delivery}

Of course, these possible benefits must be weighed against potential disadvantages. For some drugs, transdermal delivery is associated with a delayed onset of action compared with oral and parenteral administration [1]. Absorption of drug can be compromised if the patch does not properly remain in contact with the skin. Some patients develop irritant or allergic contact dermatitis leading to the discontinuation of treatment [1].

Skin irritation may result from exposure to the drug being administered or the structural components of the patch. A review of transdermal delivery systems for seven different drugs showed that between $20 \%$ and $50 \%$ of users reported skin irritation that was usually mild in severity [11]. Irritant contact dermatitis is the most common type of dermal reaction seen at patch application sites, and it is an inflammatory response localized to the site and characterized by erythema, but it may also be itchy and edematous. However, irritant contact dermatitis usually resolves without treatment after removal of the irritant [11]. Skin irritation may lead to occlusion of sweat ducts, resulting in formation of itchy, red papulomas that are also self-resolving-usually within $24 \mathrm{~h}$ of patch removal. Removal of the patch itself may cause transient erythema alone or may be accompanied by flare and edema (triple response of Lewis) [11].

\subsection{Types of Patches}

Transdermal administration is used to deliver drugs locally (e.g. anti-inflammatory agents for pain) or systemically via the circulation. Passive transdermal drug delivery systems may be categorized as either reservoir or matrix designs. In the former, the drug is stored in one or more reservoirs located between the backing of the patch and a membrane that is engineered to control the rate of diffusion into the skin [1]. In the matrix design, the drug is embedded either in the adhesive (drug-in-adhesive patches), or in a layer of matrix material between the adhesive layer and the backing. The total amount of drug delivered is related to the rate of drug delivery from the matrix, as well as being proportional to the surface area of the patch that is in contact with the skin and the duration of application.

With both passive designs, once the patch is applied to the skin, a diffusion gradient is established, and the drug moves into the stratum corneum, the outer layer of the skin (Fig. 1). Transit through the stratum corneum is carried out by diffusion through intercellular lipids [12]; this is the rate-limiting step in passive transdermal drug delivery [1]. Therefore, drugs that are suitable for passive patch technology have a small molecular mass $(<500 \mathrm{Da})$ and are lipophilic [1,13]. These drugs must be chemically stable during patch storage and during transdermal diffusion when the patch is on the patient's body. Patches are typically designed such that residual drug concentrations in the patch are low when they are applied for the recommended duration of wear time.

\subsection{Transdermal Drug Delivery Systems in Development}

No transdermal delivery systems for larger molecules and peptides are currently approved by the US FDA. Active delivery systems for such drugs are the subject of ongoing research. One approach, iontophoresis, uses administration of a low electrical current to actively drive diffusion of charged molecules across the stratum corneum without the need to increase skin permeability. Ultrasound (sonophoresis) can be used to increase permeability of the stratum corneum. Although the mechanism by which sonophoresis 
Fig. 1 Passive patch technology. Once the patch is applied to the skin, a diffusion gradient is established, and the drug moves into the stratum corneum

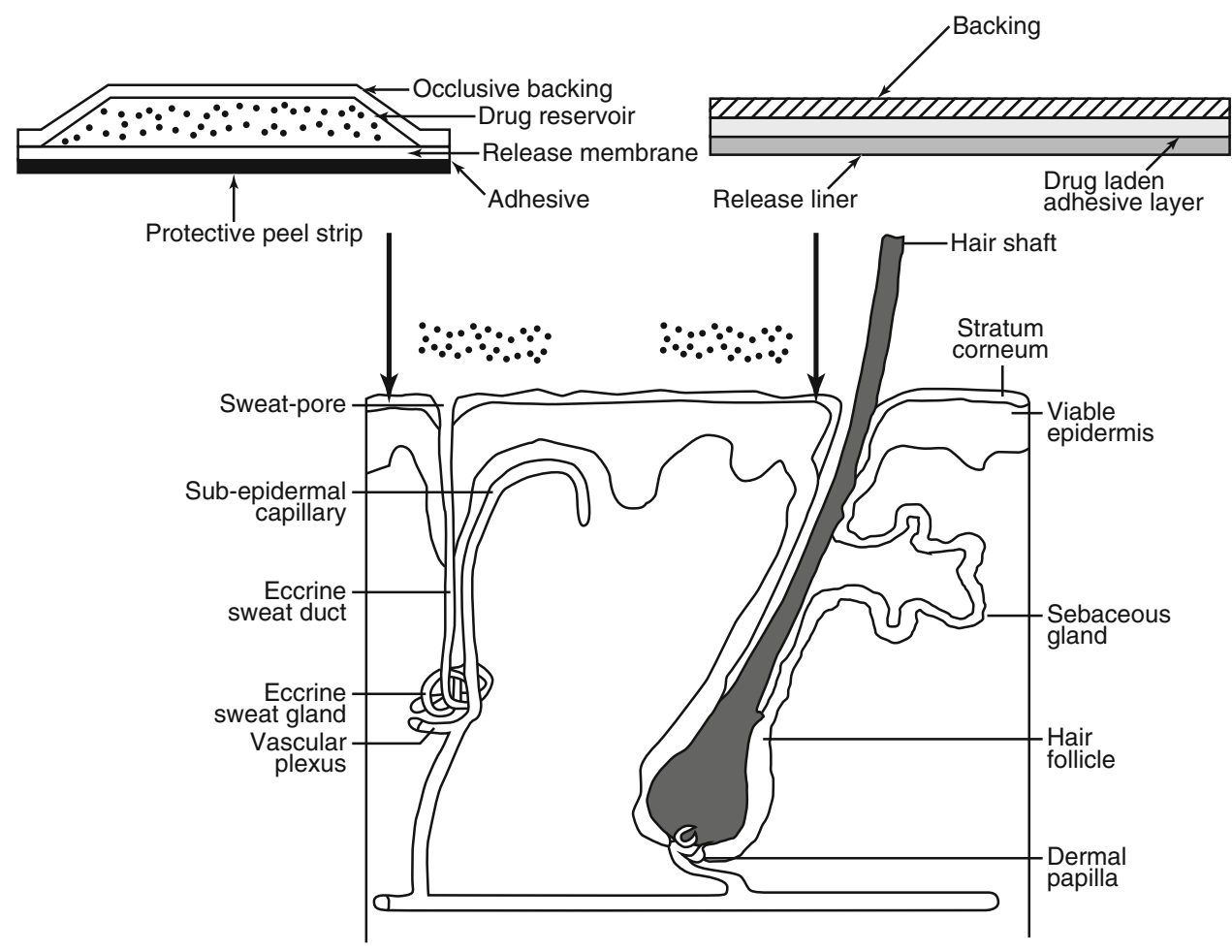

works is not completely understood, it is thought to increase permeability through a combination of cavitation (formation of gas-filled cavities), mechanical and thermal effects, and induction of convection transport [14]. Other methods such as chemical agents that facilitate drug transit through the stratum corneum, microneedle, thermal ablation, and microdermabrasion are in development but are not yet approved for administration of larger and more highly charged molecules [12].

\section{Transdermal Methylphenidate in Attention-Deficit Hyperactivity Disorder (ADHD)}

\subsection{ADHD}

In the US, about $7 \%$ of children aged 4-17 years (about 4 million) carry a diagnosis of ADHD in the community [15]. Compared with the general population, individuals with ADHD carry a higher risk of learning disabilities, mood disorders, anxiety, and disruptive behavioral disorders [16, 17]. As children mature, the resulting impairments may persist, resulting in higher rates of accidents, lower highschool graduation rates, difficulty in the workplace, and poorer psychosocial functioning [18].

All FDA-approved ADHD medication dosage forms are oral, except for one methylphenidate patch. Current guidelines recommend stimulant medications, such as dextroamphetamine, $d$ - and $d, l$-methylphenidate, or mixed salts of amphetamine, as first-line treatments for children $[18,19]$. These agents act as dopamine and norepinephrine reuptake inhibitors, and likely target frontostriatal neurocircuits [20]. The response rates are similar for short- and long-acting formulations (approximately $80 \%)$, as are the reported effect sizes $(0.91)$ [21, 22]. Methylphenidate and amphetamines share the same sideeffect profiles, the most common of which are delayed sleep onset, decreased appetite, abdominal pain, headache, rebound irritability, motor and vocal tics, and jitteriness [16].

Adherence to treatment is a challenge with most chronic disorders, and ADHD is no exception. Discontinuation and non-adherence among patients who are prescribed ADHD medication vary with the definition of adherence and the method used to measure. Analyses of large claims databases show that, on average, patients discontinue ADHD medication less than 1 year after the first prescription [23]. The need for multiple doses, inflexibility of medication duration, and inability to swallow tablets or capsules are additional considerations when treating patients with ADHD. A variety of formulations have been developed to address these issues. Liquid formulations and capsules whose contents can be sprinkled on food are available for persons who have difficulty swallowing. Both stimulants and non-stimulant medications for ADHD are available in formulations that allow for once-daily dosing. 
2.2 Overview of the Methylphenidate Transdermal System (MTS)

At this time, the methylphenidate transdermal system (MTS) is the only transdermal treatment approved by the FDA for the treatment of ADHD in the US. Efficacy has only been established in children aged 6-12 years and adolescents aged 13-17 years [4]. The MTS is a drug-inadhesive matrix patch containing a racemic mixture of $d$ and $l$-enantiomers of methylphenidate. The methylphenidate dose delivered is dependent on the size of the patch, the application site, and the wear time. Thus, a shorter wear time results in a shorter duration of action. The current design of the MTS is based, in part, on the pharmacokinetic studies showing that when the patch is worn for $9 \mathrm{~h}$, peak plasma concentrations of methylphenidate are reached at about $8 \mathrm{~h}$ after multiple patch applications, and the elimination half-life is 3-4 $\mathrm{h}$ [4]. The package insert recommends application to the hip area approximately $2 \mathrm{~h}$ before effect is needed, and the MTS patch can be worn for up to $9 \mathrm{~h}$. Four patch sizes are available $(12.5,18.75,25$, and $37.5 \mathrm{~cm}^{2}$ ), which deliver 10-, 15-, 20-, and 30-mg doses, respectively, based on a 9 -h wear time [4]. The patch can be removed prior to $9 \mathrm{~h}$ if a shorter duration of dosing is desired [24].

\subsection{Comparative Pharmacokinetics of MTS Compared with Oral Methylphenidate Formulations}

The differences between MTS and immediate- and extended-release oral methylphenidate formulations reside in their pharmacokinetic profiles. The pharmacokinetic profile of MTS was evaluated in a phase II, randomized, placebocontrolled laboratory classroom study involving 80 children aged 6-12 years who were treated for ADHD [25]. Doses were titrated to methylphenidate $10,15,20$, or $30 \mathrm{mg}$ delivered over a 9-h MTS wear time. Systemic exposure was proportional to dose, and the effectiveness was observed between the first observation at $2 \mathrm{~h}$ after patch application and $12 \mathrm{~h}$ after patch application. These observations were expanded in a second pharmacokinetic study-conducted in 35 children aged 6-12 years and 36 adolescents aged 12-16 years-that compared the pharmacokinetic profiles of $d$ - and $l$-methylphenidate enantiomers following administration of single, multiple fixed, and escalating doses of MTS or osmotic release oral system (OROS) methylphenidate $18 \mathrm{mg}$ once daily [5].

The pharmacokinetic profiles of methylphenidate following single and multiple MTS and OROS doses are shown in Fig. 2. Circulating levels of $d$-methylphenidate were higher in children than for adolescents for all dosing regimens tested [5]. For the single-dose determinations, all patients received MTS $10 \mathrm{mg} / 9 \mathrm{~h}$ or OROS methylphenidate $18 \mathrm{mg} /$ day. Blood samples were taken before dosing and at 1, 2, 4, 6, 8, 9, 10, 12, 14, 24, and $30 \mathrm{~h}$ post-dosing. Following the single dose, the concentration of $d$-methylphenidate was not measureable at the 1- or 2-h sampling times, suggesting that absorption of methylphenidate with MTS administration is delayed by about $2 \mathrm{~h}$. In contrast, serum concentrations of methylphenidate increased rapidly after administration of a single OROS methylphenidate dose. The mean time to maximum concentration $\left(t_{\max }\right)$ for $d$-methylphenidate was $10.0 \mathrm{~h}$ (range 8.00-12.0) in children and $10.0 \mathrm{~h}$ (range 6.00-12.0) in adolescents with MTS, whereas the $t_{\max }$ following a single OROS methylphenidate dose was $6.02 \mathrm{~h}$ (range 4-10) in children and $8.00 \mathrm{~h}$ (range 1-10) in adolescents [5]. The same dosing regimens were extended for 10 days for the multiple fixed-dose analyses. Accumulation (defined as the maximum concentration $\left[C_{\max }\right]$ at steady state over the $C_{\max }$ after a single dose) of $d$-methylphenidate was $34 \%$ in children and $57 \%$ in adolescents after 7 days of MTS $10 \mathrm{mg} / 9 \mathrm{~h}$ per day, and $13 \%$ in children and $19 \%$ in adolescents following 7 days of OROS methylphenidate $18 \mathrm{mg} /$ day [5]. Consistent with these accumulation data, serum methylphenidate was measurable at the 1 and $2 \mathrm{~h}$ sampling times after multiple dosing. The concentrationtime curves suggest that lower doses of methylphenidate administered by a transdermal patch compared with OROS methylphenidate could achieve the same plasma levels of $d$-methylphenidate. Trough concentrations at steady state (between days 7 and 14 of escalated dosing) were similar between MTS and OROS methylphenidate when compared across corresponding doses in the same age group. As shown in Fig. 2, with MTS administration, serum levels of $d$-methylphenidate increased and did not decline during the 9-h wear time following multiple doses. As expected with OROS methylphenidate administration, serum $d$-methylphenidate levels increased rapidly over the first $1-2 \mathrm{~h}$, and continued to increase, reaching a mean $t_{\max }$ at $6 \mathrm{~h}$ (range 4-10) after single and $8 \mathrm{~h}$ (range 4.00-10.0) after multiple fixed doses in children $6-12$ years of ages. The mean $t_{\max }$ in adolescents (13-17 years) was $8 \mathrm{~h}$ (range 1-10) after 1 day of OROS methylphenidate $18 \mathrm{mg} /$ day dosing, and was similar after 7 days [5].

Another difference of potential clinical importance between the MTS and other methylphenidate formulations is exposure to 1-methylphenidate, which appears to be higher with the MTS relative to other formulations of methylphenidate following single or multiple doses. Circulating levels of 1-methylphenidate are negligible after single or multiple doses in patients treated with oral methylphenidate and, as a result, the effects of this enantiomer have not been well characterized. The clinical implications of 1-methylphenidate absorption with the MTS, if any, remain to be elucidated [5]. 

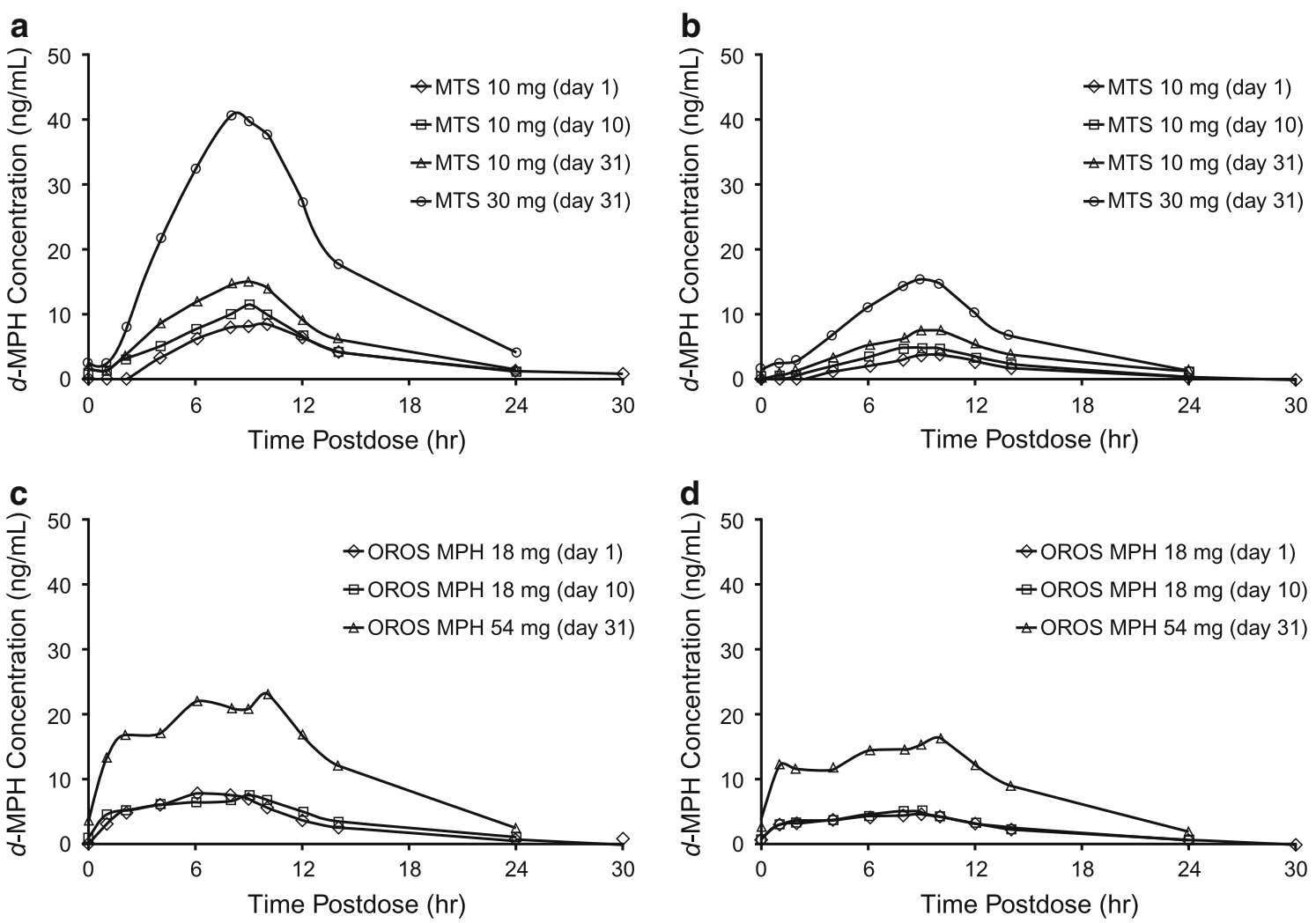

Fig. 2 Mean plasma concentration-time profiles from day 1 to 31 for $d$-methylphenidate after single and multiple doses of MTS and OROS MPH in children aged 6-12 years $(\mathbf{a}, \mathbf{c})$ and adolescents aged 13-17 years $(\mathbf{b}, \mathbf{d})$ in the pharmacokinetic population. MTS $10 \mathrm{mg}$ (day 1) indicates a single dose; MTS $10 \mathrm{mg}$ (day 10), multiple fixed dose for 7 days; MTS $10 \mathrm{mg}$ (day 31), multiple fixed dose for 28 days; MTS $30 \mathrm{mg}$, multiple escalating dose for 28 days $(10,15$,

The application site can affect the bioavailability and pharmacokinetic profile of drugs administered through the skin. A comparison of two sites found that application of MTS to the hip resulted in a significantly greater $C_{\max }$ than application to the scapula $(33.8 \pm 10.2$ vs. $26.2 \pm 11.2 \mathrm{ng} /$ $\mathrm{mL}, p=0.01$ hip vs. scapula) in boys and girls (aged 6-12 years) during a 16-h wear time [26]. The area under the curve from 0 to $16 \mathrm{~h}\left(\mathrm{AUC}_{0-16}\right)$ was also greater with hip placement, although the $t_{\max }$ was only slightly longer with hip placement.

\subsection{Phase II Efficacy Trials}

Several studies were conducted to determine the appropriate dosing range and wear times for MTS in children. In a phase II study, doses of MTS worn for $9 \mathrm{~h}$ daily were optimized over a 5-week period. In this placebo-controlled, crossover study $(N=80)$ conducted in a laboratory classroom, most children $(63 \%)$ were know to be responsive to stimulants, while the rest were treatment naive. Compared with placebo transdermal system (PTS),

20, and $30 \mathrm{mg}$ for 7 days each); OROS MPH $18 \mathrm{mg}$ (day 1), single dose; OROS MPH $18 \mathrm{mg}$ (day 10), multiple fixed dose for 7 days; OROS MPH $54 \mathrm{mg}$ (day 31), multiple escalating dose for 28 days (18, 27, 36, and $54 \mathrm{mg}$ for 7 days each). MTS methylphenidate transdermal system, OROS MPH osmotic-release oral system methylphenidate. Reprinted with permission from Pierce et al. [25]

MTS treatment was associated with significantly lower scores $(3.2 \pm 0.58$ vs. $8.0 \pm 0.58 ; p<0.0001)$ on the primary efficacy measure (mean Swanson, Kotkin, Agler, M-Flynn, and Pelham Rating Scale deportment [SKAMP D] scores) over both laboratory classroom days at postdose hours 2 through 9. The effect size, Cohen's d, for MTS based on this primary efficacy measure is 0.93 [27]. Response rates were not reported. The difference in behavioral and academic measures between MTS treatment and PTS was statistically significant by the first timepoint and $2 \mathrm{~h}$ after application, and remained improved $12 \mathrm{~h}$ after application ( $3 \mathrm{~h}$ after removal). During the dose optimization phase prior to randomization, 13 participants withdrew from the study-seven due to adverse events (AEs), one due to lack of efficacy, three withdrew consent, and two were lost to follow-up [27]. The incidence of any AE during the laboratory classroom period was $30 \%$ with MTS and $23 \%$ with PTS [27]. The most frequent AEs with MTS were decreased appetite, anorexia, headache, insomnia, and upper abdominal pain. These results suggested that a 9-h wear time was safe and well tolerated, and 
provided a broad window of efficacy with once-daily dosing.

Two studies assessed various dose and time combinations. In the first study, both dose and onset of action were assessed in 36 children aged 6-13 years [28]. Doses ranged from $0.45 \mathrm{mg} / \mathrm{h}$ to $1.8 \mathrm{mg} / \mathrm{h}$, and wear times were at least $12 \mathrm{~h}$ per day. Participants were enrolled in a summer treatment program. This study showed that based on counselor, teacher, and parent ratings of behavior, there was little or no benefit to increasing the dose above $0.45 \mathrm{mg} / \mathrm{h}$ in the structured setting. To determine the best time to apply the patch prior to the need for symptom control, parents were instructed to apply patches either 60 or $120 \mathrm{~min}$ before the start of the program activities. Although time of application had no overall effect on daily behavior, fewer behavioral problems arose during the first hour of activities when the patches were administered 120 min rather than 60 min before class. AEs were typical of those reported with methylphenidate, and the incidence of AEs increased at higher doses. The incidence of parentreported insomnia was $22 \%$ across all doses at these long wear-times [28]. Another study of similar design was conducted in 27 children [29]. In this trial, MTS doses (patch sizes $12.5,25$, or $37.5 \mathrm{~cm}^{2}$ ) were varied randomly over 24 days and worn for $8.5 \mathrm{~h}$ daily (unless moderate or severe side effects occurred, in which case patches were removed earlier). Behavior modification therapy was added on alternate weeks. This study showed that similar ADHD Rating Scale (ADHD-RS) scores could be achieved with lower MTS doses when patients received supplemental behavioral therapy [29]. As was observed in the other study by Pelham et al., the incidence of AEs appeared to be dose related. Two patients who were randomized to receive the highest dose on the first day withdrew because of AEs (tics, buccal lingual movements, and insomnia) at that dose. One child withdrew from study treatment because of a dermal reaction [29].

Before-school symptom control and functioning were assessed as secondary outcomes in a randomized, placebocontrolled, crossover designed study of 30 children with ADHD to determine the time of onset of ADHD symptom improvement following MTS application [30]. Parents were instructed to apply the MTS between $6.00 \mathrm{am}$ and $7.00 \mathrm{am}$, and before school; evaluations were based on behavior between $6.00 \mathrm{am}$ and $9.00 \mathrm{am}$. Reductions in baseline scores for the ADHD-AM-RS (ADHD-RS evaluated between $6.00 \mathrm{am}$ and $9.00 \mathrm{am}$ ) were greater during MTS treatment (67\% reduction vs. baseline) than during placebo transdermal treatment $(25 \%$ reduction vs. baseline; $p=0.003$ for MTS vs. placebo). Scores on the before-school functioning questionnaire, which investigated activities such as listening to parents and teachers, following directions, and hygiene, were also significantly better with MTS. Patterns and frequency of AEs were similar to those observed in other MTS trials [30].

\subsubsection{Variable Wear Times}

Unlike oral formulations, the MTS patch wear time can be varied. This provides patients and caretakers with the ability to modify the duration of treatment effect, and can be used to minimize side effects by limiting treatment to the times when effective symptom reduction is desired. The safety and efficacy of using variable wear times (4 and $6 \mathrm{~h}$ ) was evaluated in a phase IIb study of 117 children aged 6-12 years in an analog classroom setting over a period of 8 weeks [24]. Behavioral ratings on the SKAMP deportment scores returned to baseline levels between 2 and $4 \mathrm{~h}$ after patch removal for both wear times. For the 4-h wear time, Permanent Product Measure of Performance (PERMP) scores declined rapidly between 2 and $6 \mathrm{~h}$ after patch removal. A slower decline in PERMP scores was observed after the 6-h wear time. Most AEs were mild to moderate, and no unexpected events were reported. The most frequent AEs were decreased appetite (28\%), headache $(21 \%)$, insomnia $(20 \%)$, and abdominal pain $(12 \%)$ [24].

\subsubsection{Switching from Oral Methylphenidate}

To determine the safety and efficacy of switching from an oral methylphenidate formulation to the MTS, the effects of an abrupt switch from oral methylphenidate ER (Ritalin LA, Concerta, or Metadate controlled delivery [CD]) were assessed in a 4-week, open-label study [31]. MTS dosing was based on the previous daily oral dose of methylphenidate ER. Those previously receiving Concerta $18 \mathrm{mg}$ and Ritalin LA or Metadate CD 10 or $20 \mathrm{mg}$ were switched to MTS $10 \mathrm{mg} / 9 \mathrm{~h}$; Concerta $27 \mathrm{mg}$ and Ritalin LA or Metadate CD $30 \mathrm{mg}$ were switched to MTS $15 \mathrm{mg} / 9 \mathrm{~h}$; Concerta $36 \mathrm{mg}$ and Ritalin LA or Metadate CD $40 \mathrm{mg}$ were switched to MTS $20 \mathrm{mg} / 9 \mathrm{~h}$; and Concerta $54 \mathrm{mg}$ and Ritalin LA or Metadate CD $50 \mathrm{mg}$ were switched to MTS $30 \mathrm{mg} / \mathrm{h}$. Patients remained on their initial MTS transition dose for 1 week and then entered a 2-week dose-adjustment period. An increase or decrease in dose was permitted based on tolerability, and Clinical Global ImpressionSeverity (CGI-S) scores were assessed by investigators. After the final dose adjustment visit at the end of week 3, no further changes in dose were permitted. No dose adjustment was required for $58 \%$ of 164 children after the switch. Overall, $4 \%(6 / 164)$ required a smaller patch size (lower dose) and $38 \%$ (63/164) required a larger patch size (higher dose). Mean ADHD-RS total scores were significantly improved over baseline at study end (9.9 \pm 7.47 vs. $14.1 \pm 7.48 ; p<0.0001)$ [31]. Most patients $(68-83 \%)$ 
across doses had skin reaction scores of 0 (no reaction) or 1 (minimal erythema). Four participants withdrew because of skin reactions. The most frequently reported AEs were headache, decreased appetite, insomnia, and abdominal pain of mild to moderate intensity [31]. These results suggest that switching to MTS from oral methylphenidate is generally well tolerated and that patients may achieve better symptom control with the adjusted doses of MTS when compared with previously administered fixed oral doses of methylphenidate ER.

\subsubsection{Patch adhesion}

Patch adhesion was evaluated in two studies. In a laboratory classroom study ( $N=80$ randomized), $>90 \%$ patch surface was found to have remained adherent in $86 \%$ of the children after $9 \mathrm{~h}$ of wear [27]. Patch adhesion over $12 \mathrm{~h}$ of wear time was evaluated during an 8-day summer program, which included participation in swimming and other physical activities. Among the 36 participants during the 8-day period, 18 patches came off and another 18 required taping [27].

\section{MTS Clinical Trials (Phases III and IV)}

\subsection{Pediatric Patients (Aged 6-12 Years)}

\subsubsection{Efficacy}

In 2006, the MTS received an indication for use in pediatric patients with ADHD based on results showing efficacy with 9-h patch wear times in the classroom and community settings (Table 1) [32-36]. Findling et al. [32] conducted a 7-week, randomized, double-blind, placebocontrolled, naturalistic study assessing MTS in 270 pediatric patients with ADHD. Treatment with OROS methylphenidate was used as an active control. The primary efficacy endpoint was the change from baseline ADHDRS, Version IV (ADHD-RS-IV) total score at study end. The Conners' Teachers Rating Scale-Revised (CTRS-R) was the main secondary efficacy measure. Parents evaluated their children's response to treatment using the Conners' Parents Rating Scale-Revised (CPRS-R). The difference in change from baseline ADHD-RS-IV for MTS versus a placebo patch was statistically significant on the primary analysis ( -24.2 with MTS vs. -10.3 with placebo; $p<0.0001)$. Change from baseline CTRS-R and CPRS-R also showed statistically significant differences between MTS and placebo. The difference in change from baseline ADHD-RS-IV for OROS methylphenidate versus a placebo patch was statistically significant on the primary analysis $(-21.6$ with OROS methylphenidate vs. -10.3 with placebo; $p<0.0001)$. All measures with OROS methylphenidate were also statistically significantly better than with placebo treatment [32].

The most commonly reported AEs were decreased appetite, nausea, vomiting, and insomnia in all treatment groups, and most AEs were of mild-to-moderate intensity. Percentages of children with any AE were $76 \%$ with MTS, $69 \%$ with OROS methylphenidate, and $56 \%$ with PTS. Discontinuation rates due to AEs were 7, 2, and $1 \%$ in the MTS, OROS methylphenidate, and PTS groups, respectively [32]. The MTS patch was well tolerated, with $7.1 \%$ of patients discontinuing study treatment because of AEs compared with $2.2 \%$ in the OROS methylphenidate group and $1.2 \%$ in the placebo group. Four patients on MTS reported edema, and two patients on MTS discontinued treatment related to application-site reactions. Mild skin irritation occurred in the MTS group in the Findling et al. 2008 study [32], where $77 \%$ of the 98 patients reported no evidence $(51.5 \%)$ or minimal evidence $(25.5 \%)$ of irritation.

\subsubsection{Long-Term Safety and Tolerability}

A total of 327 patients were enrolled in a 1-year, open-label safety extension of four trials. Most $(81 \%)$ reported at least one AE [33]. Of the AEs, $98 \%$ were mild or moderate in severity and approximately $40 \%$ were considered related to the study treatment. The discontinuation rate due to AEs was $9 \%$. The majority of those who withdrew (7\%) did so because of dermal reactions.

Long-term growth data were also collected for 127 children for up to 37 months during the open-label extension study [35]. Comparisons were made with longterm growth data from 61 children who were excluded at baseline. Treatment with MTS was associated with small but significant deficits in growth parameters, including height $(0.68 \mathrm{~cm}$ less per year), weight gain $(1.3 \mathrm{~kg}$ less per year), and body mass index (BMI; 0.49 units less per year). There was an early and pronounced reduction in growth rates from 0 to 12 months followed by a period from 12 to 36 months in which the reduction in growth rates was less significant. Deficits in weight gain and BMI increases were more apparent than deficits in growth. The overall findings suggest that although MTS treatment has a small negative impact on growth, these effects attenuate over time. Patients who were above average in height, weight, or BMI at baseline were more likely to experience significant growth deficits in all parameters compared with average or small patients at baseline. Prior stimulant use, total time treated, and doses of ADHD medications were predictive of growth deficits with 


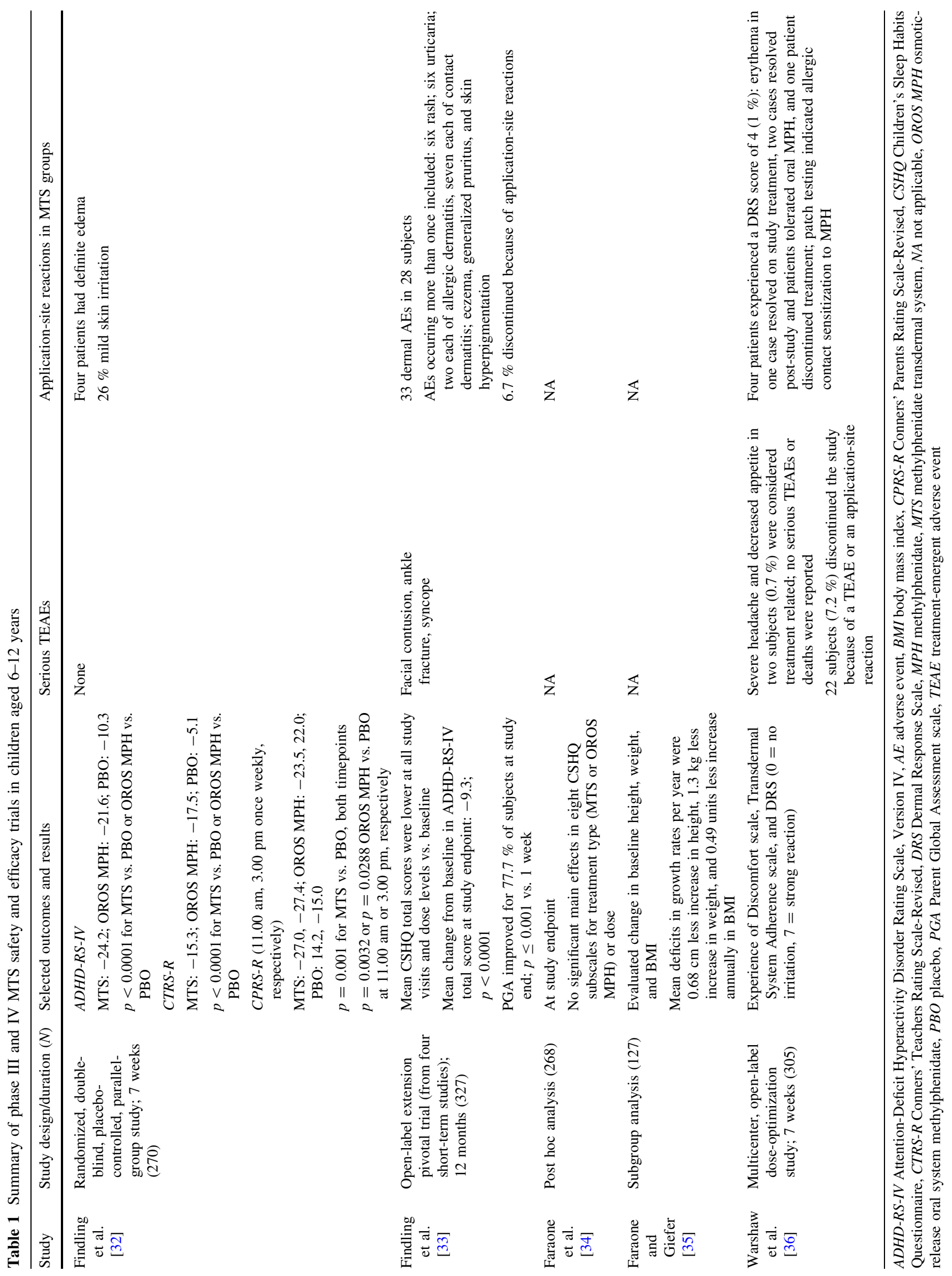


respect to expected changes in body weight and BMI, but not height [35].

\subsubsection{Sleep Quality}

The impact of MTS treatment on sleep was analyzed as a secondary endpoint in an 8-week pivotal trial [34]. The Children's Sleep Habits Questionnaire (CSHQ) was administered at baseline and at all subsequent visits for the duration of the 8-week study. There was no statistically significant difference in the frequency or severity of sleep disturbance among treatment groups. The dose of methylphenidate administered with the patch or with OROS methylphenidate was not significantly correlated with either the frequency or severity of sleep behavior problems [34]. Similar results were found in a second open-label study involving 26 patients with ADHD and a history of difficulty sleeping [37]. MTS wear times ranged from 9-12 h. Patients were randomized to one of four sequences of 9-, 10-, 11-, and 12-h wear times. Sleep latency and total sleep time were not negatively affected by the duration of wear time.

\subsubsection{Dermal Responses}

Dermal reactions were characterized in 305 children aged 6-12 years with ADHD who were enrolled in an open-label, dose-optimization study [36]. After a 4-week dose-titration period, patients continued to wear the MTS at the optimized dose of $10,15,20$, or $30 \mathrm{mg}$ for $9 \mathrm{~h}$ per day on alternating hips for an additional 3 weeks. Application-site evaluations were conducted at weeks 0 , $1,2,3,4,5$, and 8. The current application site and the site from the previous day were scored using a 7-point dermal response score (DRS), where 0 is no irritation and 7 is strong reaction spreading beyond the test site. At the scheduled visits, evaluation of the current application site showed that $46.9 \%$ of patients had DRS scores of $\leq 1$. Another $49 \%$ had DRS scores of 2, $2.0 \%$ had DRS scores of 3, and $1.0 \%$ (four patients) had DRS scores of 4 . No DRS scores $>4$ were reported at any time during the trial. In an assessment of the previous day's application sites, $82 \%$ of patients had DRS scores of $\leq 1$. DRS scores did not tend to increase with increasing MTS doses. More than $90 \%$ of patients reported either no discomfort or mild discomfort at the current or previous day's application site. Three of the four patients with a DRS score of 4 were successfully switched to oral methylphenidate. The fourth individual withdrew from the study and subsequently had a mild patch test response to methylphenidate, indicating allergic contact sensitization [36].

\subsection{Adolescent Patients (Aged 13-17 Years)}

\subsubsection{Efficacy and Safety}

Similar benefit and tolerability with MTS has been observed in adolescents diagnosed with ADHD (Table 2) [38, 39]. Safety and efficacy were evaluated in a 7-week, double-blind, randomized, placebo-controlled, communitybased study [38]. Patients were randomized to treatment with MTS or a placebo patch (PTS). A total of 215 patients were included in a 5-week dose-optimization period followed by 2 weeks on a stable dose. At study endpoint, the difference from baseline ADHD-RS-IV score was significantly greater in the MTS group than the PTS group (difference -9.96 [95\% CI -13.39 to -6.53 ]; $p<0.001$ ). Results on the CPRS also showed significant improvement with MTS compared with the PTS at study end. Frequently reported AEs were typical of those observed in clinical trials of stimulants. Dermal reactions were generally mild; however, 3 of 215 patients discontinued treatment as a result of skin irritation [38].

\subsubsection{Long-Term Safety and Tolerability}

Long-term safety and tolerability of MTS treatment in 163 adolescents (mean age $14.5 \pm 1.2$ years) were assessed in a 6-month, open-label extension study [39]. As was observed during the 7-week study, treatment-emergent AEs were typical for patients receiving stimulants and were generally mild to moderate in severity. The most frequently reported AEs were decreased appetite $(15 \%)$ and headache (12\%). A total of $54 \%$ of patients completed the extension study, with $7 \%$ (12 patients) discontinuing because of AEs [39].

\subsection{Quality of Life}

Health-related quality of life assessed using the ADHD Impact Module-Child (AIM-C), and medication satisfaction measured with the Medication Satisfaction Survey were secondary outcome measures in a variable wear-time study in 128 children aged 6-12 years [40] (Table 3). After a screening and washout period and 5-week dose titration period using 9-h wear times, outcomes with 4- and 6-h wear times were compared using a placebo-controlled, double-blind, three-way crossover design. Pooled data across MTS doses showed that both child and family quality of life increased from baseline at the post-titration visit (5 weeks) and at study end (8 weeks) [40]. Medication satisfaction was consistent at the 5- and 8-week visits, with 92 and $89 \%$ of parents reporting high satisfaction at those respective timepoints. 
Table 2 Summary of Phase III and IV MTS safety and efficacy trials in adolescents aged 13-17 years

\begin{tabular}{|c|c|c|c|c|c|c|}
\hline Study & $\begin{array}{l}\text { Study design/ duration } \\
(N)\end{array}$ & Selected outcomes & $p$-Value & Common TEAEs & Serious TEAEs & $\begin{array}{l}\text { Application-site } \\
\text { reactions }\end{array}$ \\
\hline $\begin{array}{l}\text { Findling } \\
\text { et al. } \\
\text { [38] }\end{array}$ & $\begin{array}{l}\text { Randomized, double- } \\
\text { blind, placebo- } \\
\text { controlled, parallel- } \\
\text { group study; } \\
7 \text { weeks (217) }\end{array}$ & $\begin{array}{l}\text { ADHD-RS-IV total score } \\
\text { LS mean difference for } \\
\text { MTS vs. PTS: }-9.96 \\
\text { CPRS-R total score for } \\
\text { MTS vs. PTS: }-13.48 \\
\text { CGI-I percentage very } \\
\text { much improved or much } \\
\text { improved: } \\
\text { MTS } 65 \% \\
\text { PTS } 30.6 \%\end{array}$ & $<0.001$ & $\begin{array}{l}\text { Decreased appetite, headache, } \\
\text { irritability, upper respiratory } \\
\text { tract infection }\end{array}$ & $\begin{array}{l}\text { Syncope } \\
\quad(n=1 ; \text { two } \\
\text { episodes }) \\
\text { Oppositionality }\end{array}$ & $\begin{array}{l}\text { Most reports were } \\
\text { for mild or definite } \\
\text { erythema with no } \\
\text { or mild discomfort } \\
\text { One report of } \\
\text { application-site } \\
\text { erythema and two } \\
\text { of application } \\
\text { dermatitis }\end{array}$ \\
\hline $\begin{array}{l}\text { Findling } \\
\text { et al. } \\
\text { [39] }\end{array}$ & $\begin{array}{l}\text { Open-label extension } \\
\text { study; } 6 \text { months } \\
\text { (162) }\end{array}$ & $\begin{array}{l}\text { There was significant } \\
\text { improvement in mean } \\
\text { ADHD-RS-IV total } \\
\text { scores from study entry } \\
\text { to endpoint }\end{array}$ & $<0.001$ & $\begin{array}{l}\text { Majority }(>99 \%) \text { were mild or } \\
\text { moderate in intensity, and the } \\
\text { most frequently reported TEAE } \\
\text { was decreased appetite }(15.4 \%)\end{array}$ & & $\begin{array}{l}\text { Majority }(93.6 \%) \\
\text { of dermatologic } \\
\text { reactions indicated } \\
\text { mild erythema }\end{array}$ \\
\hline
\end{tabular}

ADHD-RS-IV Attention-Deficit Hyperactivity Disorder Rating Scale, Version IV; CGI-I Clinical Global Impression-Improvement, CPRS-R Conners' Parents Rating Scale-Revised, $L S$ least squares, MTS methylphenidate transdermal system, PTS placebo transdermal system, TEAE treatment-emergent adverse event

Table 3 Summary of health-related quality-of-life trials with MTS

\begin{tabular}{|c|c|c|c|c|}
\hline Study & Study design/duration $(N)$ & Treatments & Scales & HRQL results \\
\hline $\begin{array}{l}\text { Bukstein } \\
\text { et al. } \\
\text { [42] }\end{array}$ & $\begin{array}{l}\text { Multisite, open-label study; } \\
4 \text { weeks (171) }\end{array}$ & $\begin{array}{l}\text { Abruptly switched from a stable dose of } \\
\text { MPH ER to MTS } 10,15,20 \text {, or } 30 \mathrm{mg}\end{array}$ & $\begin{array}{l}\text { AIM-C } \\
\text { Medication } \\
\text { Satisfaction } \\
\text { Survey }\end{array}$ & $\begin{array}{l}\text { AIM-C child and family HRQL mean } \\
\text { scores were above the median possible } \\
\text { score at baseline and were further } \\
\text { improved at endpoint across all MTS } \\
\text { doses } \\
93.8 \% \text { of caregivers indicated a high } \\
\text { level of satisfaction with their child's } \\
\text { use of the study medication }\end{array}$ \\
\hline $\begin{array}{l}\text { Manos } \\
\text { et al. } \\
{[40]}\end{array}$ & $\begin{array}{l}\text { Subanalysis of a phase IIb } \\
\text { multicenter, randomized, } \\
\text { placebo-controlled, three- } \\
\text { way crossover study (115) }\end{array}$ & $\begin{array}{l}\text { After } 5 \text {-week dose optimization of MTS } \\
\text { for } 9 \mathrm{~h} / \text { day, MTS was worn for } 4 \text { or } \\
6 \mathrm{~h} \text { (varied at weekly intervals) in a } \\
\text { laboratory classroom setting }\end{array}$ & $\begin{array}{l}\text { ADHD-RS } \\
\text { AIM-C } \\
\text { Medication } \\
\text { Satisfaction } \\
\text { Survey }\end{array}$ & $\begin{array}{l}\text { Mean AIM-C child and family HRQL } \\
\text { scale scores improved from baseline to } \\
\text { endpoint across all MTS doses. The } \\
\text { magnitude of improvement increased } \\
\text { with time from baseline } \\
\text { Parents/LARs indicated a high level of } \\
\text { satisfaction with their child's use of } \\
\text { MTS (visit 7: } 92.1 \% \text {; visit 10: } \\
\text { 89.1\%) }\end{array}$ \\
\hline $\begin{array}{l}\text { Frazier } \\
\text { et al. } \\
\text { [41] }\end{array}$ & $\begin{array}{l}\text { Subanalysis of a phase IIb } \\
\text { multicenter, randomized, } \\
\text { placebo-controlled, three- } \\
\text { way crossover study (117) }\end{array}$ & $\begin{array}{l}\text { After 5-week dose optimization of MTS } \\
\text { for } 9 \mathrm{~h} / \text { day, MTS was worn for } 4 \text { or } \\
6 \mathrm{~h} \text { (varied at weekly intervals) in a } \\
\text { laboratory classroom setting }\end{array}$ & $\begin{array}{l}\text { ADHD-RS } \\
\text { AIM-C } \\
\text { Medication } \\
\text { Satisfaction } \\
\text { Survey }\end{array}$ & $\begin{array}{l}\text { HRQL was not a delayed response to } \\
\text { improvement in symptoms } \\
\text { Children showed a uniform pattern of } \\
\text { improvement in HRQL that followed } \\
\text { symptom change; three distinct } \\
\text { patterns of change were found for } \\
\text { improvement in family HRQL }\end{array}$ \\
\hline
\end{tabular}

ADHD-RS Attention-Deficit Hyperactivity Disorder Rating Scale, AIM-C ADHD Impact Module-Child, LAR legally appointed representative, $M T S$ methylphenidate transdermal system, $M P H E R$ methylphenidate extended-release, $H R Q L$ health-related quality of life

To understand the temporal relationship of ADHD symptom relief, satisfaction with treatment, and family health-related quality of life, a post hoc analysis of these data was conducted [41]. Over the course of the open-label dose-titration period, improvement in ADHD symptoms, caregiver satisfaction with medication, and child health-related quality of life improved at the same time, suggesting that improvement in healthrelated quality of life might coincide with symptom amelioration. 
The feasibility of switching to the MTS from an oral agent was evaluated in a 4-week, open-label study involving 164 children aged 6-12 years [31, 42]. Patients were switched from a stable dose of one of three oral ER methylphenidate formulations (Ritalin LA, Metadate CD, Concerta) to the MTS using a dose-transition schedule [42]. Patients remained on their initial MTS transition dose for 1 week and then entered a 2-week dose-adjustment period. An increase or decrease in dose was permitted based on tolerability and CGI-S scores assessed by investigators. After the final dose-adjustment visit at the end of week 3, no further changes in dose were permitted. Scores on the AIM-C showed improvement in health-related quality of life for patients and their families after the switch. Approximately $94 \%$ of parents and caregivers reported a high level of satisfaction with the study treatment on the MTS, suggesting that the switch did not substantially disrupt health-related quality of life [42]. These findings are consistent with those of Arnold et al. [31] who evaluated efficacy and tolerability in the same trial. In the latter study, there was a significant improvement in ADHD-RS total scores after 4 weeks of using MTS, with good tolerability [31].

\section{Conclusions}

Passive transdermal delivery is a safe and effective means of administering small lipophilic molecules that has been found to improve adherence to therapy. Indicated for use in children and adolescents with ADHD, the MTS offers additional practical advantages such as once-daily dosing and flexible wear times. In addition to being clinically effective in reducing symptoms of ADHD, with the exception of generally minor dermal AEs, the MTS has a side-effect profile similar to that of other stimulants. Moreover, patients and caregivers report a significant improvement in patient and family quality of life and overall satisfaction with medication with MTS use.

Acknowledgments Manuscript preparation Ann C. Sherwood, $\mathrm{PhD}$, provided medical writing, editorial, and research assistance to the authors. Howard Hait, MS, provided consultation services for statistical analyses. This support was funded by Noven Pharmaceuticals, Inc.

Disclosures Dr. Findling receives or has received research support, acted as a consultant, received royalties from and/or served on a speaker's bureau for Abbott, Addrenex, Alexza, American Psychiatric Press, AstraZeneca, Biovail, Bracket, Bristol-Myers Squibb, Clinsys, Dainippon Sumitomo Pharma, Forest, GlaxoSmithKline, Guilford Press, Johns Hopkins University Press, Johnson \& Johnson, KemPharm Lilly, Lundbeck, Merck, National Institutes of Health, Neuropharm, Novartis, Noven, Organon, Otsuka, Oxford University Press, Pfizer, Physicians' Post-Graduate Press, Rhodes Pharmaceuticals, Roche, Sage, Sanofi-Aventis, Schering-Plough, Seaside
Therapeutics, Sepracor, Shionogi, Shire, Solvay, Stanley Medical Research Institute, Sunovion, Supernus Pharmaceuticals, Transcept Pharmaceuticals, Validus, WebMD, and Wyeth. Dr. Dinh is an employee of Noven Pharmaceuticals Inc.

Open Access This article is distributed under the terms of the Creative Commons Attribution Noncommercial License which permits any noncommercial use, distribution, and reproduction in any medium, provided the original author(s) and the source are credited.

\section{References}

1. Durand C, Alhammad A, Willett KC. Practical considerations for transdermal drug delivery. Am J Health Syst Pharm. 2012;69(2): 116-24.

2. Neupro [package insert]. Smyrna (GA): UCB, Inc; 2012.

3. Catapres-TTS [package insert]. Ridgefield (CT): Boehringer Ingelheim International GmBH; 2012.

4. Daytrana [package insert]. Miami (FL): Noven Pharmaceuticals, Inc; 2010.

5. Pierce D, Katic A, Buckwalter M, et al. Single- and multiple-dose pharmacokinetics of methylphenidate administered as methylphenidate transdermal system or osmotic-release oral system methylphenidate to children and adolescents with attention deficit hyperactivity disorder. J Clin Psychopharmacol. 2010;30(5): 554-64.

6. Jakimiuk AJ, Crosignani PG, Chernev T, et al. High levels of women's satisfaction and compliance with transdermal contraception: results from a European multinational, 6-month study. Gynecol Endocrinol. 2011;27(10):849-56.

7. Molinuevo JL, Arranz FJ. Impact of transdermal drug delivery on treatment adherence in patients with Alzheimer's disease. Expert Rev Neurother. 2012;12(1):31-7.

8. Logsdon S, Richards J, Omar HA. Long-term evaluation of the use of the transdermal contraceptive patch in adolescents. Sci World J. 2004;4:512-6.

9. Tamura G, Ichinose M, Fukuchi Y, et al. Transdermal tulobuterol patch, a long-acting $\beta(2)$-agonist. Allergol Int. 2012;61(2): 219-29.

10. Winblad B, Kawata AK, Beusterien KM, et al. Caregiver preference for rivastigmine patch relative to capsules for treatment of probable Alzheimer's disease. Int J Geriatr Psychiatry. 2007; 22(5):485-91.

11. Ale I, Lachapelle JM, Maibach HI. Skin tolerability associated with transdermal drug delivery systems: an overview. Adv Ther. 2009;26(10):920-35.

12. Prausnitz MR, Langer R. Transdermal drug delivery. Nat Biotechnol. 2008;26(11):1261-8.

13. Margetts L, Sawyer R. Transdermal drug delivery: principles and opioid therapy. Contin Educ Anaesth Crit Care Pain. 2007;7(5): $171-6$.

14. Escobar-Chávez JJ, Bonilla-Martínez D, Villegas-González MA, et al. The use of sonophoresis in the administration of drugs throughout the skin. J Pharm Pharm Sci. 2009;12(1):88-115.

15. Centers for Disease Control and Prevention. Increasing prevalence of parent-reported attention-deficit/hyperactivity disorder among children-United States, 2003 and 2007. Morb Mortal Wkly Rep. 2010;59(4):1439-43.

16. Antshel KM, Hargrave TM, Simonescu M, et al. Advances in understanding and treating ADHD. BMC Med. 2011;9:72-84.

17. Millan MJ, Agid Y, Brüne M, et al. Cognitive dysfunction in psychiatric disorders: characteristics, causes and the quest for improved therapy. Nat Rev Drug Discov. 2012;11(2):141-68. 
18. Kooij SJ, Bejerot S, Blackwell A, et al. European consensus statement on diagnosis and treatment of adult ADHD: The European Network Adult ADHD. BMC Psychiatry. 2010;10: 67-91.

19. Pliszka S, AACAP Work Group on Quality Issues. Practice parameter for the assessment and treatment of children and adolescents with attention-deficit/hyperactivity disorder. J Am Acad Child Adolesc Psychiatry. 2007;46(7):894-921.

20. Curatolo P, D'Agati E, Moavero R. The neurobiological basis of ADHD. Ital J Pediatr. 2010;36(1):79-83.

21. Elia J, Wilson Z, La Porta LS, et al. Methylphenidate transdermal system: clinical applications for attention deficit/hyperactivity disorder. Expert Rev Clin Pharmacol. 2011;4(3):311-28.

22. Faraone SV, Biederman J, Spencer TJ, et al. Comparing the efficacy of medications for ADHD using meta-analysis. Med Gen Med. 2006;8(4):4.

23. Adler LD, Nierenberg AA. Review of medication adherence in children and adults with ADHD. Postgrad Med. 2010;122(1): 184-91.

24. Wilens TE, Boellner SW, López FA, et al. Varying the wear time of the methylphenidate transdermal system in children with attention-deficit/hyperactivity disorder. J Am Acad Child Adolesc Psychiatry. 2008;47(6):700-8.

25. Pierce D, Dixon CM, Wigal SB, et al. Pharmacokinetics of methylphenidate transdermal system (MTS): results from a laboratory classroom study. J Child Adolesc Psychopharmacol. 2008;18(4):355-64.

26. González MA, Campbell D, Rubin J. Effects of application to two different skin sites on the pharmacokinetics of transdermal methylphenidate in pediatric patients with attention-deficit/ hyperactivity disorder. J Child Adolesc Psychopharmacol. 2009; 19(3):227-32.

27. McGough JJ, Wigal SB, Abikoff $\mathrm{H}$, et al. A randomized, doubleblind, placebo-controlled, laboratory classroom assessment of methylphenidate transdermal system in children with ADHD. J Atten Disord. 2006;9(3):476-85.

28. Pelham WE Jr, Manos MJ, Ezzell CE, et al. A dose-ranging study of a methylphenidate transdermal system in children with ADHD. J Am Acad Child Adolesc Psychiatry. 2005;44(6):522-9.

29. Pelham WE, Burrows-Maclean L, Gnagy EM, et al. Transdermal methylphenidate, behavioral, and combined treatment for children with ADHD. Exp Clin Psychopharmacol. 2005;13(2): 111-26.

30. Wilens TE, Hammerness P, Martelon M, et al. A controlled trial of the methylphenidate transdermal system on before-school functioning in children with attention-deficit/hyperactivity disorder. J Clin Psychiatry. 2010;71(5):548-56.

31. Arnold LE, Bozzolo DR, Hodgkins P, et al. Switching from oral extended-release methylphenidate to the methylphenidate transdermal system: continued attention-deficit/hyperactivity disorder symptom control and tolerability after abrupt conversion. Curr Med Res Opin. 2010;26(1):129-37.

32. Findling RL, Bukstein OG, Melmed RD, et al. A randomized, double-blind, placebo-controlled, parallel-group study of methylphenidate transdermal system in pediatric patients with attention-deficit/hyperactivity disorder. J Clin Psychiatry. 2008;69(1): 149-59.

33. Findling RL, Wigal SB, Bukstein OG, et al. Long-term tolerability of the methylphenidate transdermal system in pediatric attention-deficit/hyperactivity disorder: a multicenter, prospective, 12-month, open-label, uncontrolled, phase III extension of four clinical trials. Clin Ther. 2009;31(8):1844-55.

34. Faraone SV, Glatt SJ, Bukstein OG, et al. Effects of once-daily oral and transdermal methylphenidate on sleep behavior of children with ADHD. J Atten Disord. 2009;12(4):308-15.

35. Faraone SV, Giefer EE. Long-term effects of methylphenidate transdermal delivery system treatment of ADHD on growth. J Am Acad Child Adolesc Psychiatry. 2007;46(9):1138-47.

36. Warshaw EM, Squires L, Li Y, Civil R, et al. Methylphenidate transdermal system: a multisite, open-label study of dermal reactions in pediatric patients diagnosed with ADHD. Prim Care Companion J Clin Psychiatry. 2010;12(6). pii: PCC.10m00996.

37. Ashkenasi A. Effect of transdermal methylphenidate wear times on sleep in children with attention deficit hyperactivity disorder. Pediatr Neurol. 2011;45(6):381-6.

38. Findling RL, Turnbow J, Burnside J, et al. A randomized, doubleblind, multicenter, parallel-group, placebo-controlled, dose-optimization study of the methylphenidate transdermal system for the treatment of ADHD in adolescents. CNS Spectr. 2010;15(7):419-30.

39. Findling RL, Katic A, Rubin R, et al. A 6-month, open-label, extension study of the tolerability and effectiveness of the methylphenidate transdermal system in adolescents diagnosed with attention-deficit/hyperactivity disorder. J Child Adolesc Psychopharmacol. 2010;20(5):365-75.

40. Manos M, Frazier TW, Landgraf JM, Weiss M, Hodgkins P. HRQL and medication satisfaction in children with ADHD treated with the methylphenidate transdermal system. Curr Med Res Opin. 2009;25(12):3001-10.

41. Frazier TW, Weiss M, Hodgkins P, et al. Time course and predictors of health-related quality of life improvement and medication satisfaction in children diagnosed with attention-deficit/ hyperactivity disorder treated with the methylphenidate transdermal system. J Child Adolesc Psychopharmacol. 2010;20(5): 355-64.

42. Bukstein OG, Arnold LE, Landgraf JM, et al. Does switching from oral extended-release methylphenidate to the methylphenidate transdermal system affect health-related quality-of-life and medication satisfaction for children with attention-deficit/hyperactivity disorder? Child Adolesc Psychiatry Ment Health. 2009;3(1):39-41. 